\title{
Unusual case of a protruding mass in the esophagus successfully treated by endoscopic submucosal dissection
}

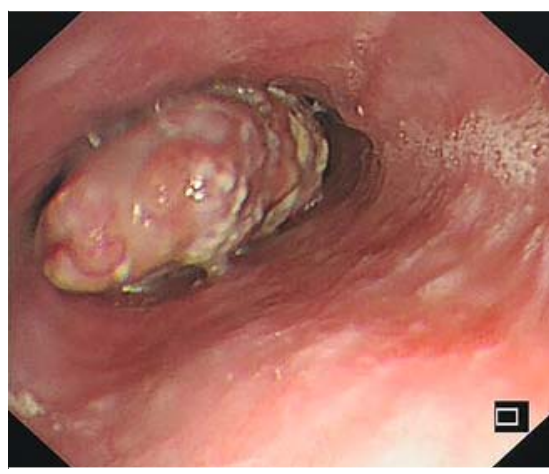

- Fig. 1 Endoscopic view of the mass in the esophagus.

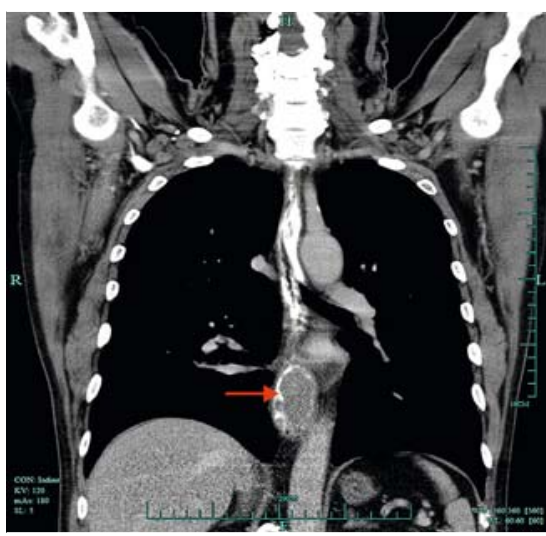

- Fig. 2 Contrast-enhanced computed tomography scan (coronal plane) showing an intraluminal mass (red arrow) in the lower esophagus.

A 65-year-old man presented with a history of progressive dysphagia for 1 month. His physical examination and blood tests showed no abnormalities. He underwent upper gastrointestinal endoscopy three times, which showed a bulky protruding mass in the esophagus at $34-39 \mathrm{~cm}$ from the incisors ( Fig. 1). Pathologic findings all revealed inflammatory hyperplasia of epithelial cells and subepithelial granulation tissue. A contrast-enhanced computed tomography (CT) scan showed an intraluminal mass in the lower esophagus (> Fig. 2), with no

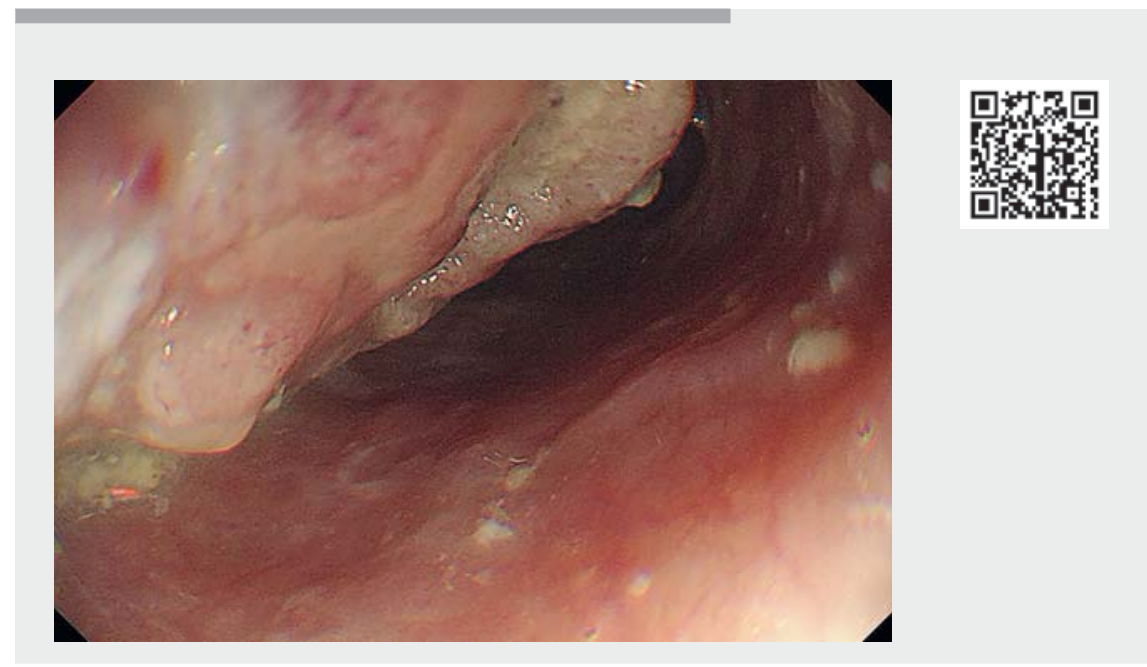

Video 1 Endoscopic submucosal dissection is performed to remove a large polypoid esophageal mass.

evidence of mediastinal lymphadenopathy or any metastases in the chest or abdominal organs. After a multidisciplinary team discussion, we performed endoscopic submucosal dissection (ESD) ( $\vee$ Video 1 ), and the lesion was successfully resected en bloc ( $\triangleright$ Fig. $\mathbf{3}$ ).

Histopathology revealed malignant squamous cells on the surface and sarcomalike spindle cells in the stroma ( $\triangleright$ Fig.4). The malignant squamous cells were well differentiated and invading the muscularis mucosa. The sarcoma-like components showed no significant dysplasia with only reactive fibroblastic proliferation and inflammatory granulocytic infiltration. Immunohistochemistry showed the squamous cells stained positively for cytokeratin and the stromal cells for vimentin. These findings are consistent with the general features of esophageal pseudosarcoma, which is a rare subtype of spindle cell carcinoma (SpCC) [1]. SpCC is characteristically a polypoid mass with intermingled spindle cell and squamous cell components [2]. Psuedosarcoma was identified by Lane as a sub-

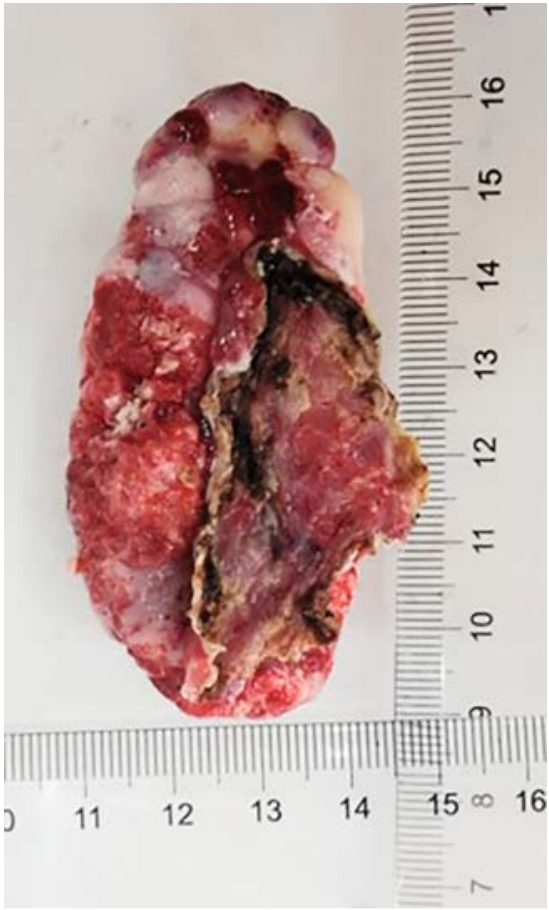

- Fig. 3 Macroscopic appearance of the resected tumor specimen. 


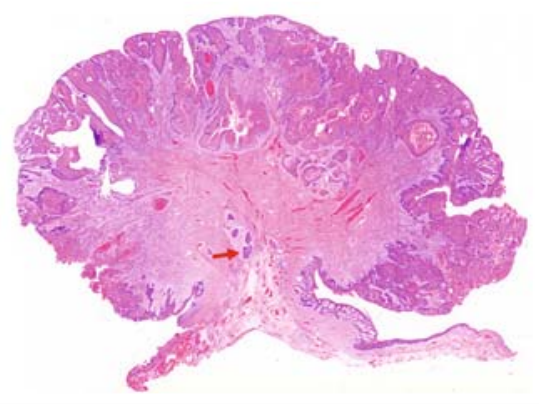

- Fig. 4 Histopathological appearance of the tumor showing a polypoid tumor with bulky sarcoma-like components and superficial malignancy, with invasion of squamous carcinoma cells into the muscularis mucosa (red arrow).

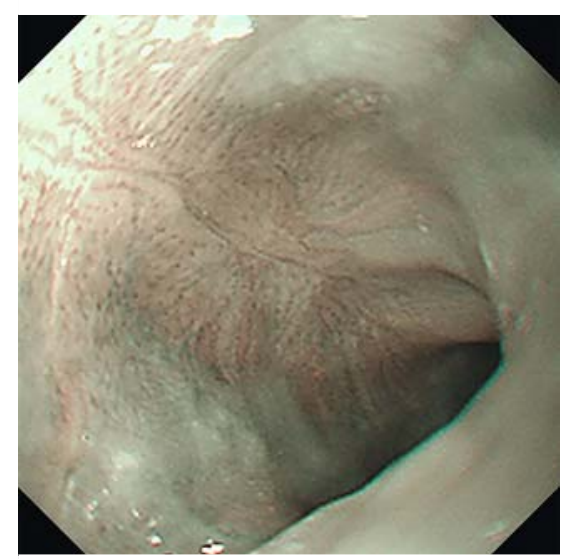

- Fig. 5 Surveillance endoscopy with narrow-band imaging after 6 months showing a well-healed scar and no evidence of tumor.

type of SpCC in which the epithelial cells are carcinomatous while the sarcomalike cells are a non-neoplastic, reactive fibroblastic proliferation [3].
The patient did not undergo further surgical resection or chemoradiotherapy owing to the early staging (T1aNOM0) of the tumor. Surveillance endoscopy after 6 months showed satisfactory wound healing and no residual or recurrent tumor ( Fig.5). To the best of our knowledge, this is the first reported case of a pseudosarcoma treated by ESD. ESD allows accurate evaluation of the tumor and can hopefully provide curative resection for early lesions.

Endoscopy_UCTN_Code_CCL_1AB_2AC_3AB

\section{Competing interests}

The authors declare that they have no conflict of interest.

The authors

\section{Bin $\mathrm{Ye}^{1,{ }^{*}}$, Jun $\mathrm{Li}^{2,{ }^{*}}$, Feng Liu' ${ }^{2} \odot$}

1 Department of Gastroenterology, The Fifth Affiliated Hospital of Wenzhou Medical University, Lishui Hospital of Zhejiang University, Lishui, China

2 Digestive Endoscopy Center, Shanghai Tenth People's Hospital, Tongji University School of Medicine, Shanghai, China

\section{Corresponding author}

\section{Feng Liu, MD}

Digestive Endoscopy Center, Shanghai Tenth People's Hospital, Tongji University School of Medicine, 301 Mid. Yanchang Road,

Shanghai, 200072, China

drliuffeng@hotmail.com

\section{References}

[1] Li X, Song X, Zhao X et al. The alterations of cytokeratin and vimentin protein expressions in primary esophageal spindle cell carcinoma. BMC Cancer 2018; 18: 356

[2] Iascone C, Barreca M. Carcinosarcoma and pseudosarcoma of the esophagus: two names, one disease-comprehensive review of the literature. World J Surg 1999; 23: 153-157

[3] LANE N. Pseudosarcoma (polypoid sarcomalike masses) associated with squamous-cell carcinoma of the mouth, fauces, and larynx; report of ten cases. Cancer 1957; 10: 19-41

\section{Bibliography}

Endoscopy 2021; 53: E435-E436

DOI 10.1055/a-1333-0915

ISSN 0013-726X

published online 27.1.2021

(c) 2021. Thieme. All rights reserved. Georg Thieme Verlag KG, Rüdigerstraße 14, 70469 Stuttgart, Germany

\section{ENDOSCOPY E-VIDEOS \\ https://eref.thieme.de/e-videos}

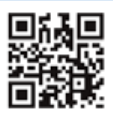

Endoscopy E-Videos is a free access online section, reporting on interesting cases and new

techniques in gastroenterological endoscopy. All papers include a high quality video and all contributions are freely accessible online.

This section has its own submission website at https://mc.manuscriptcentral.com/e-videos

\footnotetext{
* Contributed equally.
} 